\title{
In Vitro Stimulation by Long-Acting Thyroid Stimulator of Thyroid Glucose Oxidation
} and ${ }^{32} \mathrm{P}$ Incorporation into Phospholipids

\author{
James B. Field, Adrienne Remer, Gail Bloom, and Joseph P. Kriss \\ From the Clinical Research Unit and the Department of Medicine, University \\ of Pittsburgh School of Medicine, Pittsburgh, Pennsylvania (15213), and the \\ Departments of Medicine and Radiology, Stanford University School of \\ Medicine, Palo Alto, California 94304
}

A в S T R A C T Long-acting thyroid stimulator (LATS) increased glucose oxidation and ${ }^{32} \mathrm{P}$ incorporation into phospholipids in in vitro experiments with dog thyroid slices. The time course of the response was different from that obtained with thyroid-stimulating hormone (TSH), but was very similar to the delayed effect observed in vivo. During a $45 \mathrm{~min}$ incubation, $\mathrm{TSH}$, but not LATS increased glucose oxidation, whereas in longer experiments up to $6 \mathrm{hr}$, both substances augmented ${ }^{14} \mathrm{CO}_{2}$ production. Amounts of pooled human gamma globulin equivalent to LATS were inactive. Although TSH stimulated ${ }^{32} \mathrm{P}$ incorporation into phospholipids during a $2 \mathrm{hr}$ incubation, LATS was ineffective. In longer incubations, from $4 \frac{1}{2}$ to $8 \mathrm{hr}$, LATS did increase ${ }^{32} \mathrm{P}$ incorporation. The stimulatory effect of LATS was not abolished by anti-TSH antibody capable of neutralizing human TSH. Effects of LATS were also obtained with beef and pig thyroid slices. In addition to stimulation of glucose oxidation in dog thyroid slices, LATS occasionally also stimulated glucose oxidation in dog spleen and liver slices. Despite a 54-fold increase in LATS concentration, a satisfactory dose-response curve could not be demonstrated when ${ }^{14} \mathrm{CO}_{2}$ production was measured.

This work was presented before the joint meeting of the American Society for Clinical Investigation and the American Federation for Clinical Research in Atlantic City, N. J. 30 April 1967.

Received for publication 15 December 1967 and in revised from 5 March 1968.

\section{INTRODUCTION}

Although long-acting thyroid stimulator (LATS) has been demonstrated in the plasma of many patients with Graves' disease, its etiologic relationship to the various clinical manifestataions of this disease is unclear (1-6). Both thyroid-stimulating hormone (TSH) and LATS increase release of thyroid hormone from the thyroid gland in vivo, but the time course of their action is quite distinct. LATS has also been reported to mimic the following effects of TSH: (a) Increase in ${ }^{131} \mathrm{I}$ uptake by the thyroid gland $(7) ;(b)$ Increase in vacuole formation and the height of acinar cells with a reduction in the intensity of the staining of colloid (7-9); and (c) In vitro stimulation of ${ }^{131} \mathrm{I}$ release from prelabeled guinea pig (10) and mouse (11) thyroid. All of these results are compatible with, but do not necessarily prove, the concept that LATS could be responsible for the development of Graves' disease. The present in vitro studies were initiated to determine whether LATS reproduced other metabolic effects of TSH on the thyroid gland that might be relevant to the increased function of the gland and essential for the development of thyrotoxicosis. Pinchera, Pinchera, and Stanbury had previously reported that LATSpositive serum did not increase $\mathrm{O}_{2}$ consumption or glucose- $1-{ }^{14} \mathrm{C}$ oxidation by human thyroid slices obtained from a patient whose serum contained LATS (6). While the present studies were in progress, Scott, Good, and Ferguson reported that 
LATS increased glucose uptake and oxidation and ${ }^{32} \mathrm{P}$ incorporation into phospholipids in sheep thyroid slices (12).

\section{METHODS}

The method for obtaining and incubating thyroid slices has been reported previously (13). $200 \mathrm{mg} / 100 \mathrm{ml}$ of bovine albumin was added to the buffer. In the experiments measuring glucose-1 $1{ }^{14} \mathrm{C}$ oxidation, the glucose concentration was $1 \mathrm{mg} / \mathrm{ml}$ and each flask contained $0.1 \mu \mathrm{c}$ of glucose- $1-{ }^{14} \mathrm{C}$. The radioactivity was added to the flasks at the beginhing of the incubation for the $45 \mathrm{~min}$ experiments. When incubations were of longer duration, glucose- $1-{ }^{14} \mathrm{C}$ was added to the flasks $45 \mathrm{~min}$ before the termination of the experiment. The reactions were stopped and the ${ }^{14} \mathrm{CO}_{2}$ counted as previously described (13). When ${ }^{22} \mathrm{P}$ incorporation into phospholipids was measured, the incubation volume was $2-\mathrm{ml}$, which contained $0.8 \mathrm{mg}$ of glucose and $10 \mu \mathrm{c}$ of or thophosphate ${ }^{-22} \mathrm{P}$. The radioactivity was added to the flasks at the beginning of the experiment when the incubation period was $2 \mathrm{hr}$. For longer incubations, ${ }^{32} \mathrm{P}$ was added to the flasks $2 \mathrm{hr}$ before the termination of the experiment. ${ }^{32} \mathrm{P}$ incorporation into phospholipids was measured as previously reported (14). In the experiments in which the effects of TSH and LATS on glucose oxidation by liver, kidney, spleen, and testes slices were studied, these tissues were obtained from the same dog whose thyroid gland was used. TSH, LATS, and $\gamma$-globulin were dissolved or diluted in KrebsRinger bicarbonate buffer containing albumin before addition to the appropriate flasks.

LATS was prepared and purified from sera having high LATS concentration by the method of Kriss, Pleshakov, and Chien (1). During the course of these experiments, several different LATS preparations were used with potencies that ranged from 4 to $7 \mathrm{U} / \mathrm{mg}$, as defined by Kriss et al. (1). Bovine TSH ( $2 \mathrm{U} / \mathrm{mg}$ ) was kindly provided by the Endocrinology Study Section, National Institutes of Health. Human TSH $(0.6 \mathrm{U} / \mathrm{mg})$ was a gift from the National Pituitary Agency and Dr. Robert Bates, National Institutes of Health. Antibovine TSH was generously provided by Dr. Ira Pastan, Na- tional Institutes of Health and by Dr. Seymour Reichlin, University of Rochester School of Medicine. $0.02 \mathrm{ml}$ completely inhibited the effect of $5 \mathrm{mU}$ of TSH based on stimulation of glucose-1- ${ }^{14} \mathrm{C}$ oxidation. Gamma globulin was a commercial preparation of concentrated human gamma globulin containing $165 \mathrm{mg} / \mathrm{ml}$ (Immu-G, Parke, Davis \& Company, Detroit, Mich.). ${ }^{32} \mathrm{P}(45 \mathrm{mc} / \mathrm{mg})$ was purchased from E. R. Squibb \& Sons, New York, and glucose- $1{ }^{14} \mathrm{C}$ (6.3 mc/mmole) was obtained from the Nuclear-Chicago Corporation, Des Plaines, III.

\section{RESULTS}

The data in Table I demonstrate that $1 \mathrm{U}$ of LATS does not increase ${ }^{14} \mathrm{CO}_{2}$ production from glucose$1{ }^{14} \mathrm{C}$ by dog thyroid slices during a $45 \mathrm{~min}$ incubation, whereas $0.5 \mathrm{mU}$ of $\mathrm{TSH}$ caused marked stimulation. An amount of gamma globulin equivalent to the LATS had no significant effect on glucose oxidation. In contrast to the negative results obtained during a $45 \mathrm{~min}$ incubation, the data in Table II demonstrate that LATS significantly increased glucose oxidation when the incubation period was prolonged to $6 \mathrm{hr}$. In general, the stimulation produced by LATS was approximately equivalent to that of $0.5 \mathrm{mU}$ of TSH. Gamma globulin equivalent in weight to that of LATS had no significant effect on base line glucose oxidation during the 6-hr incubation period. The time course of the stimulation induced by both $\mathrm{TSH}$ and LATS is presented in Table III. In each experiment, thyroid slices from the same dog were incubated for a variable period of time. Consistent with the data in Table I, LATS did not increase glucose oxidation during a $45 \mathrm{~min}$ incubation. However, during longer incubations, LATS stimulated glucose $-1{ }^{14} \mathrm{C}$ oxidation. In one experiment, an effect of LATS was present during a $2 \mathrm{hr}$ incuba-

TABLE I

Failure of LATS to Stimulate Thyroid-Slice Glucose Oxidation during a 45 Min Incubation

\begin{tabular}{ccccc}
\hline \multirow{2}{*}{$\begin{array}{c}\text { Experiment } \\
\text { No. }\end{array}$} & \multicolumn{4}{c}{${ }^{14} \mathrm{CO}_{2} \mathrm{cpm} / \mathrm{g}$ of tissue } \\
\cline { 2 - 5 } & Buffer & TSH & LATS & $\gamma$-Globulin \\
\hline 1 & $27,397 \pm 645$ & $54,623 \pm 5060^{*}$ & $27,432 \pm 548$ & $24,039 \pm 2415$ \\
2 & $13,979 \pm 777$ & $25,316 \pm 1410^{*}$ & $13,944 \pm 1110$ & - \\
3 & $17,611 \pm 517$ & $28,398 \pm 1135^{*}$ & $17,404 \pm 1055$ & - \\
\hline
\end{tabular}

The amount of $\gamma$-globulin was equivalent in weight to that of LATS. The results are the averages \pm SEM of triplicate determinations.

${ }^{*} P<0.01$. 
TABLE II

LATS Stimulaton of Thyroid-Slice Glucose Oxidation during a $6 \mathrm{Hr}$ Incubation

\begin{tabular}{ccccc}
\hline \multirow{2}{*}{$\begin{array}{c}\text { Experiment } \\
\text { No. }\end{array}$} & \multicolumn{4}{c}{${ }^{14} \mathrm{CO}_{2} \mathrm{cpm} / \mathrm{g}$ of tissue } \\
\cline { 2 - 5 } & Buffer & TSH & LATS & $\gamma$-Globulin \\
\hline & & $0.5 m U$ & 1 U & $14,416 \pm 1132$ \\
2 & $12,171 \pm 398$ & $21,594 \pm 1774^{*}$ & $17,074 \pm 322^{*}$ & $4,712 \pm 222$ \\
3 & $4,941 \pm 473$ & $7,774 \pm 708 \ddagger$ & $7,760 \pm 320^{*}$ & $10.786 \pm 652$ \\
4 & $12,045 \pm 131$ & $20,363 \pm 384^{*}$ & $21,223 \pm 2848 \ddagger$ & $12,530 \pm 737$ \\
5 & $12,829 \pm 1205$ & $28,116 \pm 2560^{*}$ & $19,384 \pm 1860 \ddagger$ & - \\
6 & $20,535 \pm 1192$ & $27,864 \pm 3456$ & $31,540 \pm 3366 \ddagger$ & - \\
\hline
\end{tabular}

The amount of $\gamma$-globulin was equivalent in weight to that of LATS. The results are the averages \pm SEM of triplicate determinations. The glucose- ${ }^{14} \mathrm{C}$ was added during the last $45 \mathrm{~min}$ of the incubation.

* $P<0.01$.

$\ddagger P<0.05$.

tion, but no attempt was made to determine the earliest time at which a response could be detected. In incubations of $2-4 \mathrm{hr}$, the effect of TSH was somewhat greater than that of LATS. By the end of $5 \frac{1}{2}-6 \mathrm{hr}$ incubations, stimulation due to LATS and TSH was approximately equivalent.

In vivo satisfactory dose-response curves have been obtained with LATS (1), and Adams reported that the response in the McKenzie assay was steeper than that obtained with TSH (15). In contrast, the results in Table IV indicate that $0.17 \mathrm{U} /$ flask of LATS significantly increased ${ }^{14} \mathrm{CO}_{2}$ production but there was not a progressive increment, despite a 50-fold increase in the amount of LATS tested. This could not be attributed to the slices being maximally stimulated, since greater glucose- $1-{ }^{14} \mathrm{C}$ oxidation could be produced by larger amounts of TSH. In experiment 3 , $\gamma$-globulin did significantly increase glucose oxidation, as compared to buffer alone. However, the amount of stimulation was less than an equivalent weight of LATS. The explanation for $\gamma$-globulin stimulation in this single experiment is not clear. In most experiments measuring glucose oxidation, the effect of LATS did not exceed that of $0.5 \mathrm{mU}$ of TSH. The in vivo effects of LATS are not inhibited by antibody to TSH, but are neutralized by antihuman gamma globulin antibody $(1,16-18)$. The data in Table $\mathrm{V}$ indicate that LATS stimulation of glucose oxidation is not abolished by anti-TSH antibody. Antibody by itself had no effect on basal glucose oxidation, but completely inhibited the stimulation caused by $0.5 \mathrm{mU}$ of either bovine or human TSH. Since the anti-

TABLE III

Effect of Increasing Time of Incubation on LATS Stimulation of Thyroid-Slice Glucose Oxidation

\begin{tabular}{ccccc}
\hline \multirow{2}{*}{$\begin{array}{c}\text { Experiment } \\
\text { No. }\end{array}$} & \multicolumn{4}{c}{${ }^{4} \mathrm{CO}_{2} \mathrm{cpm} / \mathrm{g}$ of tissue } \\
\cline { 2 - 5 } & Time & Buffer & TSH & LATS \\
\hline \multirow{2}{*}{1} & 45 & $17,611 \pm 517$ & $28,398 \pm 1135^{*}$ & $17,404 \pm 1055$ \\
& 210 & $10,356 \pm 419$ & $19,978 \pm 577^{*}$ & $17,762 \pm 1100^{*}$ \\
& 330 & $11,018 \pm 419$ & $12,260 \pm 614$ & $14,226 \pm 469^{*}$ \\
& 120 & $7,507 \pm 220$ & $15,570 \pm 1290^{*}$ & $11,556 \pm 1170 \ddagger$ \\
& 240 & $6,795 \pm 360$ & $10,873 \pm 1465 \ddagger$ & $9,442 \pm 350^{*}$ \\
& 360 & $14,270 \pm 3370$ & $20,841 \pm 7878$ & $26,952 \pm 157^{*}$
\end{tabular}

Glucose-1-14 $\mathrm{C}$ was present only during the last $45 \mathrm{~min}$ of the incubation. The results are averages $\pm \mathrm{SEM}$ of triplicate determinations. In each experiment, all of the slices came from a single thyroid gland.

$* P<0.01$.

$\ddagger P<0.05$. 
TABLE IV

Effect of Increasing Doses of LATS on Stimulation

\begin{tabular}{|c|c|c|c|c|}
\hline \multirow{3}{*}{$\begin{array}{l}\text { Experiment } \\
\text { No. }\end{array}$} & \multirow[b]{3}{*}{ Control } & & \multicolumn{2}{|c|}{${ }^{14} \mathrm{CO}_{2} \mathrm{cpm} / \mathrm{g}$ of tissue } \\
\hline & & \multicolumn{3}{|r|}{ LATS, U/flask } \\
\hline & & 0.17 & 0.50 & 1.5 \\
\hline 1 & $21,665 \pm 2495$ & $33,194 \pm 3122 *$ & $35,205 \pm 810 \ddagger$ & $31,159 \pm 4765$ \\
\hline 2 & $37,953 \pm 509$ & $45,767 \pm 1140 \ddagger$ & $48,877 \pm 2493 \ddagger$ & $44,648 \pm 2024^{*}$ \\
\hline 3 & $26,634 \pm 112$ & $29,497 \pm 1107^{*}$ & $32,892 \pm 1326 \ddagger$ & $33,962 \pm 2752^{*}$ \\
\hline
\end{tabular}

$\gamma$-Globulin was used in a weight equivalent to $4.5 \mathrm{U}$ of LATS. Incubation was for $4 \mathrm{hr}$ and glucose- ${ }^{14} \mathrm{C}$ was added during the last $45 \mathrm{~min}$ of the incubation. The results are averages $\pm \mathrm{SEM}$ of triplicate determinations.

$* P<0.05$.

$\ddagger P<0.01$.

body was produced by injection of bovine TSH and LATS is of human origin, it was important to document that human TSH would also be neutralized by the antibody.

Although LATS augments glucose oxidation in dog thyroid slices, the data in Table VI demonstrate that this effect is not always unique for this tissue. LATS significantly increased glucose oxidation of liver slices in one of three experiments, and in two of three experiments with spleen slices. In those experiments in which ${ }^{14} \mathrm{CO}_{2}$ production was stimulated by LATS, an equivalent amount of gamma globulin was without effect, indicating that this was not a nonspecific response to protein. No stimulation by LATS was seen in two experiments with testes slices or one with kidney slices. In contrast to this complete lack of specificity, $\mathrm{TSH}$ did not influence ${ }^{14} \mathrm{CO}_{2}$ accumulation in liver, spleen, or kidney. In one of two experiments, TSH increased glucose oxidation in testes slices. An absence of TSH stimulation of glucose oxidation in liver and testes has previously been reported (13). Evidence has accumulated that indicates LATS can stimulate thyroid gland function in guinea pigs (19), mice (7), sheep (12), and humans $(20,21)$, but not in chicks (22). In vitro effects of LATS on glucose oxidation, similar to those of TSH, can also be obtained using pig and beef thyroid slices (Table VII). Both TSH and LATS increased glucose oxidation in pig thyroid slices, whereas in beef thyroid slices both substances significantly inhibited ${ }^{14} \mathrm{CO}_{2}$ production. This reduction of glucose oxidation mediated by small amounts of TSH confirms the results previously published by Merlevede, Weaver, and Landau (23) and is in contrast to the effect of larger doses that produce stimulation (13). Gamma globulin was without effect on glucose oxidation in either pig or beef thyroid slices. The results in Table VIII confirm the observation of Scott et al.

TABLE V

Failure of TSH Antibody $(A b)$ to Inhibit LATS Stimulation of Thyroid-Slice Glucose Oxidation

\begin{tabular}{|c|c|c|c|c|c|c|}
\hline \multirow{2}{*}{$\begin{array}{c}\text { Experiment } \\
\text { No. }\end{array}$} & \multicolumn{6}{|c|}{${ }^{14} \mathrm{CO}_{2} \mathrm{cpm} / \mathrm{g}$ of tissue } \\
\hline & Control & $\mathrm{TSH}$ & TSH plus Ab & LATS & LATS plus Ab & $\mathrm{Ab}$ \\
\hline 1 & $13,122 \pm 971$ & $\begin{array}{c}0.5 \mathrm{mU} \\
25,941 \pm 3150^{*}\end{array}$ & $13,096 \pm 624$ & $\begin{array}{c}1 U \\
20,736 \pm 2485 \ddagger\end{array}$ & $21,284 \pm 765^{*}$ & $13,880 \pm 1195$ \\
\hline 2 & $16,463 \pm 1943$ & $29,459 \pm 385^{*}$ & $16,409 \pm 2084$ & - & 一 & $16,673 \pm 1905$ \\
\hline
\end{tabular}

$0.02 \mathrm{ml}$ of rabbit anti TSH plasma (Ab) was added to the appropriate flasks. Bovine TSH was used in experiment 1 and human TSH in experiment 2 . The incubation was for four hours and glucose- ${ }^{14} \mathrm{C}$ was added during the last 45 minutes of the incubation. The results are the averages \pm SEM of triplicate determinations.

$* P<0.01$.

$\ddagger P<0.05$. 


\begin{tabular}{cccc}
\hline 4.5 & \multicolumn{1}{c}{9} & TSH & $\gamma$-Globulin \\
\hline $47,267 \pm 6102 \ddagger$ & $43,805 \pm 3675 \ddagger$ & $0.5 m U$ & $25,675 \pm 3223$ \\
$49,714 \pm 2056 \ddagger$ & $48,922 \pm 806 \ddagger$ & $48,840 \pm 549 \ddagger$ & $37,999 \pm 3346$ \\
$36,233 \pm 3629^{*}$ & $36,317 \pm 3566^{*}$ & $33,904 \pm 5091^{*}$ & $29,350 \pm 185 \ddagger$ \\
\hline
\end{tabular}

that LATS stimulates ${ }^{32} \mathrm{P}$ incorporation into phospholipids (12). During $4 \frac{1}{2}-8 \mathrm{hr}$ incubations, LATS significantly increased ${ }^{32} \mathrm{P}$ incorporation into phospholipids when compared with buffer or with an equivalent amount of gamma globulin. Similar to the experiments in which glucose oxidation was measured, stimulation by LATS is delayed when compared with TSH, and did not exceed that of $1 \mathrm{mU}$ of TSH. LATS did not increase ${ }^{32} \mathrm{P}$ incorporation into phospholipids during a $2 \mathrm{hr}$ incubation period, but did so when the incubation was extended to $5 \frac{1}{2} \mathrm{hr}$.

\section{DISCUSSION}

The present results confirm and extend the observation of Scott et al. (12) that LATS stimulates glucose oxidation and ${ }^{32} \mathrm{P}$ incorporation into phospholipids in thyroid slices. Examination of the data of Scott et al. does not allow any conclusions about the time course of the effect of LATS in comparison with that of TSH. The present results clearly demonstrate that the onset of LATS stimulation has a longer latent period than that of $\mathrm{TSH}$, since the latter increased glucose oxidation

TABLE VI

Effect of LATS on Glucose Oxidation of Slices of Various Tissues

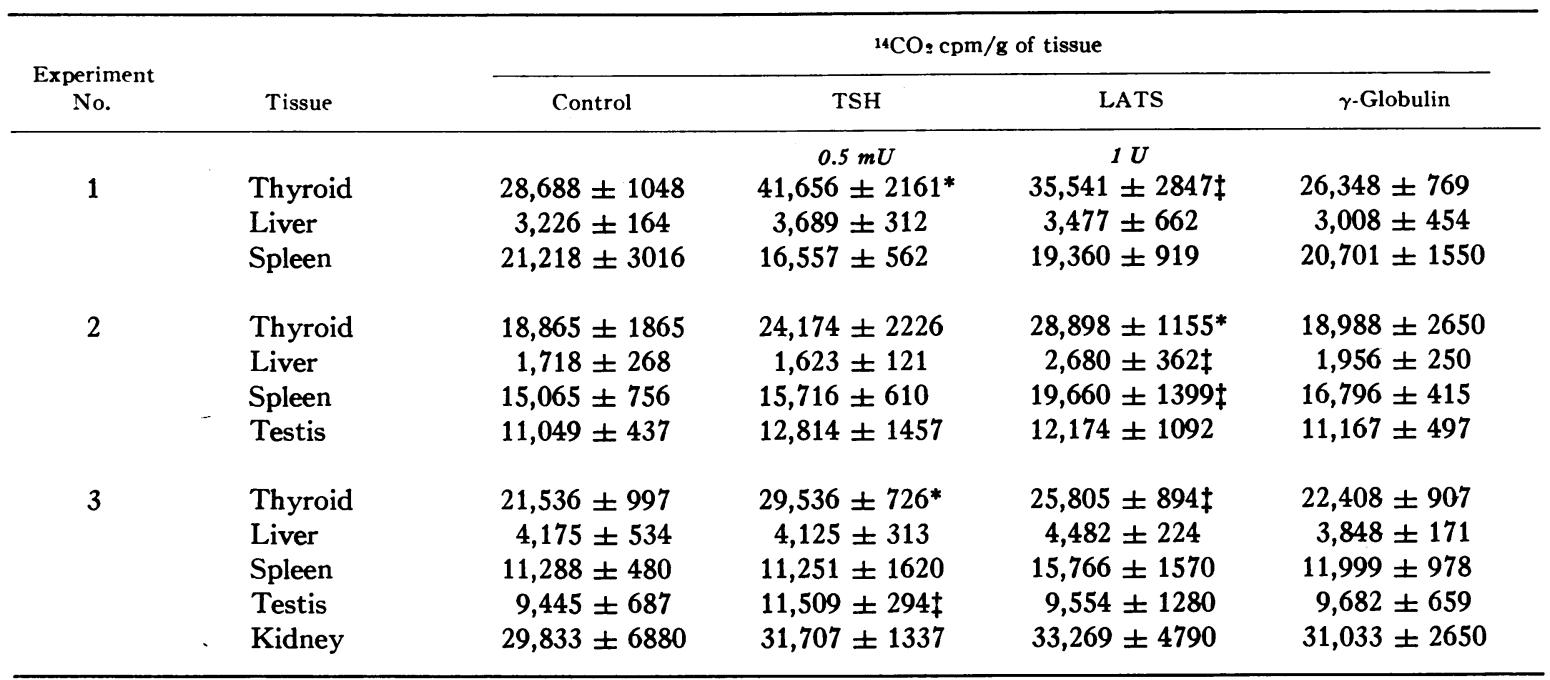

The amount of $\gamma$-globulin was equivalent in weight to that of LATS. The incubation was for $4 \mathrm{hr}$ and glucose-1-14C was added during the last $45 \mathrm{~min}$ of the incubation. The results are averages \pm SEM of triplicate determinations. In each experiment, all of the tissues came from a single dog.

$* P<0.01$.

$\ddagger P<0.05$. 
TABLE VII

Effect of LATS on Glucose Oxidation of Pig and Beef Thyroid Slices

\begin{tabular}{lcccc}
\hline & \multicolumn{4}{c}{${ }^{14} \mathrm{CO}_{2} \mathrm{cpm} / \mathrm{g}$ of tissue } \\
\cline { 2 - 5 } Species & Control & TSH & LATS & $\gamma$-Globulin \\
\hline Pig & $11,350 \pm 687$ & $17,675 \pm 199^{*}$ & $15,204 \pm 165^{*}$ & $10,667 \pm 357$ \\
Beef & $20,146 \pm 830$ & $3,836 \pm 618^{*}$ & $9,708 \pm 1460^{*}$ & $18,071 \pm 1500$ \\
Beef & $16,658 \pm 939$ & $7,425 \pm 676^{*}$ & $11,732 \pm 918^{*}$ & $14,697 \pm 874$
\end{tabular}

The amount of $\gamma$-globulin was equivalent in weight to that of LATS. The total incubation was for $4 \mathrm{hr}$ when pig thyroid was used and $2 \frac{1}{2} \mathrm{hr}$ when beef thyroid was studied. Glucose $-{ }^{14} \mathrm{C}$ was present only during the last $45 \mathrm{~min}$ of the incubation. The results are the averages \pm SEM of triplicate determinations.

$* P<0.01$.

in thyroid slices during a $45 \mathrm{~min}$ incubation, whereas no effect of the former was apparent in incubations shorter than $120 \mathrm{~min}$. In this respect, the in vitro effect of LATS is very similar to its in vivo action on ${ }^{131} \mathrm{I}$ release, which is characterized by a longer latent period and a more prolonged effect than that of TSH. The data in Table III indicate that TSH stimulation is greater during the shorter incubation periods, whereas, by $5-6 \mathrm{hr}$, the increase due to LATS tends to be greater. The characteristics of the time course of action of LATS in vitro probably explain the failure of Pinchera et al. (6) to detect stimulation of glucose oxidation by thyroid slices incubated with LATS positive plasma, since their incubations were only for $80 \mathrm{~min}$. The in vitro experiments measuring ${ }^{32} \mathrm{P}$ incorporation into phospholipids also demonstrates that LATS has a delayed onset of action when compared with TSH. In addition to this temporal distinction between LATS and TSH, another possible difference was suggested by the finding of Scott et al. that LATS stimulated ${ }^{32} \mathrm{P}$ incorporation almost equally into both lecithin and monophosphatidylinositol, whereas TSH increased incorporation into the latter compound preferentially (12). The patterns of labeling of phospholipids were not evaluated in the present studies. Our observation that LATS did not increase ${ }^{32} \mathrm{P}$ incorporation into phospholipids during the 2-hr incubations, but did increase glucose oxidation during a similar interval, would be consistent with the effect on ${ }^{14} \mathrm{CO}_{2}$ production

TABLE VIII

Effect of LATS on ${ }^{32} P$ Incorporation into Phospholipid by Dog Thyroid Slices

\begin{tabular}{|c|c|c|c|c|c|c|}
\hline \multirow{2}{*}{$\begin{array}{l}\text { Experimental } \\
\text { No. }\end{array}$} & \multirow[b]{2}{*}{ Incubation time } & \multicolumn{5}{|c|}{${ }^{32} \mathrm{P}$ incorporation $\mathrm{cpm} / \mathrm{mg}$} \\
\hline & & Control & $\gamma$-Globulin & TSH & TSH & LATS \\
\hline & $h r$ & & & $1 \mathrm{mU}$ & $10 \mathrm{mU}$ & $1 U$ \\
\hline 1 & 4.5 & $11 \pm 0.6$ & - & $18 \pm 0.4^{*}$ & - & $15 \pm 1.8 f$ \\
\hline 2 & 5.5 & - & $85 \pm 5.8$ & $131 \pm 7.0^{*}$ & - & $109 \pm 5.3 \ddagger$ \\
\hline 3 & 5.5 & - & $45 \pm 3.8$ & $68 \pm 3.2 \ddagger$ & $91 \pm 5.4^{*}$ & $65 \pm 4.3 \ddagger$ \\
\hline 4 & 8 & $197 \pm 6.5$ & $206 \pm 1.6$ & $245 \pm 23.4$ & $274 \pm 20.2 \ddagger$ & $235 \pm 7.0^{*}$ \\
\hline \multirow[t]{2}{*}{5} & 2 & 一 & $62 \pm 7.1$ & $80 \pm 2.1 \ddagger$ & - & $67 \pm 3.7$ \\
\hline & 5.5 & - & $47 \pm 1.2$ & $67 \pm 6.4 \ddagger$ & - & $64 \pm 1.8^{*}$ \\
\hline \multirow[t]{3}{*}{6} & 2 & - & $13 \pm 1.7$ & $17 \pm 1.4$ & - & $14 \pm 1.7$ \\
\hline & 5.5 & - & $9 \pm 1.1$ & $25 \pm 4.3 \ddagger$ & - & $14 \pm 0.3^{*}$ \\
\hline & 7.5 & - & $10 \pm 1.1$ & $18 \pm 2.6 \ddagger$ & - & $14 \pm 1.0 \ddagger$ \\
\hline
\end{tabular}

The amount of $\gamma$-globulin was equivalent in weight to that of LATS. In the $2 \mathrm{hr}$ incubation, ${ }^{32} \mathrm{P}$ was present during the entire experiment, whereas in the longer incubations it was added during the last $2 \mathrm{hr}$. In each experiment, slices from the same dog thyroid were used for the entire experiment. The results are the averages \pm SEM of triplicate experiments. $* P<0.01$.

$\ddagger P<0.05$. 
not being dependent on that of phospholipid synthesis. A similar conclusion concerning these two effects of TSH has also been presented (14).

The interpretation of these in vitro effects of LATS on glucose oxidation and phospholipid synthesis in relation to a possible etiologic significance in thyrotoxicosis must remain speculative. If LATS were the cause of Graves' disease, it should be capable of stimulating those metabolic functions that would be essential for the development and maintenance of increased thyroid cell function. Effects caused by TSH provide a convenient comparison for any substance that might be implicated in the genesis of thyrotoxicosis. Even though TSH stimulation of glucose oxidation and phospholipid synthesis are well documented, it is not clear what their relationship is to increased thyroid hormone synthesis and release. Thus, although LATS satisfies the criterion of reproducing the effects of TSH on glucose oxidation and phospholipid synthesis, it certainly is not warranted to conclude at this time that it is the etiologic agent in Graves' disease.

The explanation for the delayed effect of LATS both in vivo and in vitro is not apparent. It has been clearly established that LATS is a 7-S gamma globulin (1), but various techniques which have been used to disrupt the gamma globulins have given different results in terms of the time course of action of the resulting fragments. Meek, Jones, Lewis, and Van der Laan reported that after fractionation of the gamma globulins the peak effect was observed in $2 \mathrm{hr}$ to be similar to that caused by TSH (17). Similar results were obtained by Dorrington, Carneiro, and Munro after papain digestion of LATS, whereas peptic digestion of the gamma globulin produced fragments which had the delayed effect characteristic of LATS (18). Cysteine reduction of the peptic digest resulted in activity that had the time characteristics of TSH. Dorrington et al. suggested that the molecular size was important in determining the time course of response in the McKenzie assay and that renal clearance might be an important factor (18). Obviously, the latter could not be pertinent to the in vitro studies reported in this paper. The more rapid effect of papain digests of LATS was not inhibited by antibody to TSH, indicating that LATS is not TSH complexed to gamma globulin (24).
Current evidence suggests that $\mathrm{TSH}$ exerts many of its effects on the thyroid as a result of stimulation of adenylcyclase and increased intracellular levels of $3^{\prime} 5^{\prime}$ cyclic adenosine monophosphate (AMP) (25-27). Although it is possible that LATS might also produce its effects as a result of increased accumulation of $3^{\prime} 5^{\prime}$ cyclic AMP, it would be difficult to explain the delayed action of LATS on this basis, since the dibutyryl derivative of cyclic AMP stimulated glucose oxidation in thyroid slices during $45 \mathrm{~min}$ of incubation. Thus the delay in LATS effect would have to be explained by a relatively slow fixation of LATS to the thyroid cell membrane or slow activation of the adenylcyclase, or, alternatively, the stimulation induced by LATS may involve an entirely different mechanism. McKenzie has suggested the possibility that LATS may act by inhibiting cyclic nucleotide phosphodiesterase, the enzyme normally degrading cyclic AMP (28).

Because of the very nature of the in vivo bioassay for LATS, it has not been possible to evaluate the tissue specificity of the response. The results shown in Table VI indicate that the response is not completely specific for thyroid slices. A1though glucose oxidation was stimulated by LATS in thyroid slices in each experiment, a positive response was observed with liver slices in one of the three experiments and spleen slices in two of three studies. In two experiments with testes slices and one utilizing kidney slices, LATS had no effect, indicating that the response to LATS may still retain some specificity. Pertinent to this is the conflicting data in the literature concerning the unique ability of thyroid homogenate to inhibit the effect of LATS in the McKenzie assay system. Kriss et al. reported that homogenates of liver, kidney, testis, brain, and adrenal, but not spleen, also caused reduction in LATS activity (1). Such homogenates were only one-tenth as effective as thyroid homogenate. In contrast, Berumen, Lobsenz, and Utiger found no inhibition of LATS by fractions of liver, kidney, or muscle (29). Furthermore, Beall and Solomon found microsomes of these tissues, as well as those of the pancreas, adrenals, and lymph nodes, to be inactive (30).

\section{ACKNOWLEDGMENT}

This research was supported by grants AM-06865, AM07642, and GA-05838 from the National Institutes of Health, U. S. Public Health Service, Bethesda, Md. 


\section{REFERENCES}

1. Kriss, J. P., V. Pleshakov, and J. R. Chien. 1964. Isolation and identification of the long-acting thyroid stimulator and its relation to hyperthyroidism and circumscribed pretibial myxedema. J. Clin. Endocrinol. Metab. 24: 1005.

2. McKenzie, J. M. 1965. Pathogenesis of Graves' Disease: Role of the long-acting thyroid stimulator. $J$. Clin. Endocrinol. Metab. 25: 424. (Review.)

3. Noguchi, A., H. Kurihara, and S. Sato. 1960. Clinical studies of a long-acting thyroid stimulator. $J$. Clin. Endocrinol. Metab. 24: 160.

4. Carneiro, L., K. J. Dorrington, and D. S. Munro. 1966. Relation between long-acting thyroid stimulator and thyroid function in thyrotoxicosis. Lancet. 2: 878.

5. Adams, D. D. 1965. Pathogenesis of the hyperthyroidism of Graves' disease. Brit. Med. J. 1: 1015.

6. Pinchera, A., M. G. Pinchera, and J. B. Stanbury. 1965. Thyrotropin and long-acting thyroid stimulator assays in thyroid disease. J. Clin. Endocrinol. Metab. 25: 189.

7. McKenzie, J. M. 1960. Further evidence for a thyroid activator in hyperthyroidism. J. Clin. Endocrinol. Metab. 20: 380 .

8. Major, P. W., and D. S. Munro. 1960. Thyroidstimulating activity in human sera. J. Endocrinology. 20: 19. (Abstr.)

9. Shishiba, Y., D. H. Solomon, and G. N. Beall. 1967. Comparison of the early effects of thyrotropin and long-acting thyroid stimulator on thyroidal secretion. Endocrinology, 80: 957.

10. El Kabir, D. J. 1963. The in vitro assay of thyrotropin. In Thyrotropin. S. C. Werner, editor. Charles C Thomas, Springfield. 253.

11. Brown, J., and D. S. Munro. 1966. A new in vitro assay for thyroid-stimulating hormone. J. Physiol. 182: 9.

12. Scott, T. W., B. F. Good, and K. A. Ferguson. 1966. Comparative effects of long-acting thyroid stimulator and pituitary thyrotropin on the intermediate metabolism of thyroid tissue in vitro. Endocrinology. 79: 949.

13. Field, J. B., I. Pastan, P. Johnson, and B. Herring. 1960. Stimulation in vitro of pathways of glucose oxidation in thyroid by thyroid-stimulating hormone. J. Biol. Chem. 235: 1863.

14. Oka, H., and J. B. Field. 1966. Effects of ions on TSH stimulation of $\mathrm{P}^{22}$ incorporation into thyroid slice phospholipid. Am. J. Physiol. 211: 1357.

15. Adams, D. D. 1961. Bioassay of long-acting thyroid stimulator (LATS): the dose response relationship. J. Clin. Endocrinol. Metab. 21: 799.

16. McKenzie, J. M., and J. Fishman. 1960. Effects of antiserum in bioassay of thyrotropin and thyroid ac- tivator of hyperthyroidism. Proc. Soc. Expertl. Biol. Med. 105: 126.

17. Meek, J. C., A. E. Jones, U. J. Lewis, and W. P. VanderLaan. 1964. Characterization of the long-acting thyroid stimulator of Graves' disease. Proc. Nat. Acad. Sci. 52: 342.

18. Dorrington, K. J., L. Carneiro, and D. S. Munro. 1965. Chemical studies on the long-acting thyroid stimulator. In Current Topics in Thyroid Research. C. Cassano and M. Andreoli, editors. Academic Press Inc., New York. 455.

19. Adams, D. D. 1958. The presence of an abnormal thyroid-stimulating hormone in the serum of some thyrotoxic patients. J. Clin. Endocrinol. Metab. 18: 699.

20. Bjorkman, S. E., T. Denneberg, and I. Hedenskog. 1961. Clinical evaluation of the thyroid-stimulating hormone activity in exophthalmos. Acta Endocrinol. 38: 577.

21. Arnaud, C. D., H. A. Kneubuhler, V. L. Seiling, B. K. Wightman, and N. H. Engbring. 1965. Response of the normal human to infusions of plasma from patients with Graves' disease. J. Clin. Invest. 44: 1287.

22. Lepp, A., and L. Oliner. 1967. Failure of long-acting thyroid stimulator globulin (LATS) and serum to stimulate thyroid function in the chick. Endocrinology. 80: 369 .

23. Merlevede, W., G. Weaver, and B. R. Landau. 1963. Effects of thyrotropic hormone on carbohydrate metabolism in thyroid slices. J. Clin. Invest. 42: 1160.

24. Kriss, J. P., V. Pleshakov, A. Rosenblum, and J. R. Chien. 1965. Studies on the formation of long-acting thyroid stimulator globulin (LATS) and the alteration of its biologic activity by enzymatic digestion and partial chemical degradation. In Current Topics in Thyroid Research. C. Cassano and M. Andreoli, editors. Academic Press Inc., New York. 433.

25. Pastan, I. 1966. The effect of dibutyryl cyclic $3^{\prime} 5^{\prime}$ AMP on the thyroid. Biochem. Biophy's. Res. Commun. 25: 14 .

26. Gilman, A. G., and T. W. Rall. 1966. Studies on the relationship of cyclic $3^{\prime} 5^{\prime}$ AMP (CA) to thyroid-stimulating hormone action in beef thyroid slices. Federation Proc. 25 : 617. (Abstr.)

27. Pastan, I., and R. Katzen. 1967. Activation of adenylcyclase in thyroid homogenates by thyroid-stimulating hormone. Biochem. Biophys. Res. Commun. 29: 792.

28. McKenzie, J. M. 1967. The long-acting thyroid stimulator: its role in Graves' disease. Recent Progr. Hormone Res. 23: 1.

29. Berumen, F. O., I. L. Lobsenz, and R. D. Utiger. 1967. Neutralization of the long-acting thyroid stimulator by thyroid subcellular fractions. J. Lab. Clin. Med. 70: 640 .

30. Beall, G. N. and D. H. Solomon. 1966. Inhibition of long-acting thyroid stimulator by particulate thyroid fractions. J. Clin. Invest. $45: 552$. 